\title{
LA PRIMERA CRISIS DEL ESPECTACULO CINEMATOGRAFICO Y SU INFLUENCIA EN EL ESPECTACULO TEATRAL
}

Jorge Urrutia

El formalismo y el estructuralismo nos convencieron de la importancia de considerar siempre los límites del texto. Sin embargo, la nueva crítica no puede dejar de tener en cuenta que son numerosos los aspectos extratextuales que influyen en la composición del texto literario y dejan su huella en la estructura. $\mathrm{Al}$ fin y al cabo, un texto no es sino la fijación de una peculiar conjunción de códigos y lo intratextual surge del enfrentamiento y la coincidencia de lo extratextual.

Mi intención en estas páginas es, precisamente, la de mostrar un ejemplo de cómo aspectos exteriores, sociológicos en el caso escogido, influyen en la composición.

No me refiero sólo a la fuerza impositiva que tiene la moda, las corrientes mayoritarias de la época. Ni siquiera a la norma de verosimilitud dictada por los géneros y que ha sabido diagnosticar la poética francesa. Me refiero a hechos similares, en el teatro, a que - por ejemplo- el autor reciba el pago de sus derechos según las páginas escritas, como sucede en la novela por entregas.

Ese motivo socioliterario puede explicar la estructura de algunas novelas decimonónicas, alargadas exageradamente al incluir documentos o numerosas historias secundarias. La cara de Dios, novela por entregas de Ramón María del ValleInclán, llama la atención por la cantidad de puntos y aparte que ofrece cada página. El sencillísimo truco de convertir, en muchos capítulos, la frase en un párrafo permitió ocupar mucho espacio. Un hecho puramente externo explica, también el absurdo final de una novela por entregas de Manuel Fernández y González. Es una anécdota conocida. El director del periódico en el que se publicaba el folletín le advirtió de que su novela no interesaba a los lectores y de que convendría sustituirla. Veía, sin embargo, el director un grave inconveniente y era que Fernández y González manejaba gran número de personajes, por lo que concluir con la trama debería ser necesariamente largo. Pero el novelista tranquilizó al director asegurándole que ello no tenía importancia. Lo fundamental era ter- 
minar pronto la obra y empezar a publicar otra nueva. Dicho y hecho. Fernández y González buscó una razón para que todos sus personajes embarcaran en un buque. Sabemos lo peligrosos que son esos mares de Dios. El barco naufragó, los personajes se ahogaron sin salvarse ninguno y la novela dio fin de ese modo.

Acudamos a ejemplos del teatro. En el verano de 1980 una nota de prensa nos hacía saber que, en Wolverhampton, la Open Air Theatre Company se había visto obligada a estrenar una versión de Blancanieves con sólo dos enanitos, debido a que «las autoridades municipales (que auspiciaban las representaciones) pusieron estrictos límites a los gastos de la compañía» ${ }^{1}$.

$\mathrm{El}$ «Magazine» del Observer, por su parte, anunciaba el siete de octubre de 1979 que The Court Theatre convocaba de nuevo su Young Writers Festival, al que podrían presentar obras todos los jóvenes autores. El concurso no obligaba a ningún tema o estilo, pero sí exigía que los personajes no fueran más de seis «as this makes it much easier to cast» ${ }^{2}$. Los convocantes no pueden dejar a un lado el elevado costo de un montaje - el premio consiste en la puesta en escena por una compañía profesional de la obra ganadora- que exija muchos actores. Un crítico no avisado, estudiando la producción dramática de los jóvenes autores británicos actuales pudiera atribuir a motivos equivocados la escritura de obras con pocos personajes.

No es posible dejar a un lado la influencia que los distintos espectáculos ejercen entre sí. Unos pueden atraer, dirigir o condicionar los públicos de otros. En distintos lugares he dedicado páginas a estudiar las posibles influencias entre lenguajes o a la situación del cine en la cadena espectacular de las «variétés» ${ }^{3}$; ahora me gustaría destacar condicionamientos sociológicos que obligan al nacimiento de determinadas obras dramáticas.

José Francos Rodríguez proporciona, en su libro El teatro en España. $1908^{4}$, una interesante estadística de la que voy a partir. En dicho año se entrenaron en Madrid cuatrocientas veintisiete obras de teatro que, por el número de actos, se distribuyen del siguiente modo:

$\begin{array}{lr}\text { Obras en cinco actos } & 4 \\ \text { Obras en cuatro actos } & 4 \\ \text { Obras en tres actos } & 23 \\ \text { Obras en dos actos } & 17 \\ \text { Obras en un acto } & 379\end{array}$

El mismo autor, al año siguiente, publica El teatro en España. 1909 , en el que figura una estadística similar. Se estrenaron cuatrocientas once obras, distribuidas así:

1 ABC de Sevilla, 29 de agosto de 1980.

2 Me proporciona el recorte de prensa el Dr. Don Rafael Portillo.

3 En el libro Imago litterae.cine.literatura, (Sevilla: Alfar), 1984. También en «Hacia una semiótica diacrónica (el nacimiento del lenguaje cinematográfico)», comunicación al Congreso sobre Semiótica e Hispanismo; Madrid, 1983.

4 (Madrid: Imprenta de «Nuevo Mundo»), s.f.

5 (Madrid: Imprenta de Bernardo Rodriguez), s.f. 


$\begin{array}{lr}\text { Obras en cinco actos } & 1 \\ \text { Obras en cuatro actos } & 3 \\ \text { Obras en tres actos } & 18 \\ \text { Obras en dos actos } & 12 \\ \text { Obras en un acto } & 377\end{array}$

¿A qué se debe la proliferación de obras en un solo acto? ¿Por qué los dramaturgos españoles de los años 1908 y 1909 sienten esa predilección por las obras cortas? ¿Hay alguna tradición, alguna toma de postura estética, algún nuevo movimiento literario?

Algunos teatros mayores, como el mismo Apolo, representan a veces obras en un solo acto, pero la máxima demanda tiene su origen en los numerosos pequeños locales en los que el espectáculo teatral se entremezclaba con otra clase de espectáculos.

No me refiero a aquellos salones del último quinquenio del siglo XIX, en los que se desarrollaba el conocido como 'género ínfimo'. Allí, algunos números de 'variétés' se resolvieron por medio de cortas películas cuya proyección sustituía las actuaciones en vivo de magos, ilusionistas, payasos o bailarinas. José Francos Rodríguez, en su libro de 1909, también nos explica cómo se organizaron aquellos locales mixtos: «Al empezar la fiebre de los cinematógrafos, cundió la noticia de que eran una mina. ¡Fulano ha hecho un capital con las películas! ¡Aquél guarda un fortunón amañado con las ganancias de su cine! La envidia del bien ajeno y el nocivo deseo de enriquecerse pronto y con liviano esfuerzo sugirieron a muchos el propósito de acometer aquellas fáciles empresas, que reproducían en nuestro tiempo la fábula del rey Midas. En cuanto había un solar a propósito se edificaba en él un barracón, y con unos cuantos números de gimnasia o de canto, de taumaturgia barata o de flamenquismo a pecios convencionales, y varios millares de metros de cintas cinematográficas, ¡a ganar dinero! Se multiplicaron las barracas, favorecidas por el público, y este favor indujo a muchos a afrontar los riesgos de construir locales más acondicionados, y se empezó la larga serie de teatrillos que hay en Madrid y en Barcelona especialmente» ${ }^{6}$.

Juan Antonio Cabero, autor de la más útil Historia de la cinematografía española que poseemos, nos proporciona datos nuevos: "Lo curioso del caso fue que aun siendo el cinematógrafo un invento imperfectísimo, los empresarios teatrales madrileños presintieron en él a un enemigo terrible para la taquilla y se aprestaron a recibirle, no de uñas, como hubiera sido lógico, sino por el procedimiento que creyeron más eficaz: implantándolo ellos mismos en sus coliseos como fin de fiesta, al igual que hicieron con otras novedades, según tenían por costumbre.// En el primer teatro donde hizo su aparición fue en el Romea, de la calle de Carretas, el día 30 de octubre de 1896. Después del cartel zarzuelero, en que se representaban El certamen nacional, Charivari y Ensalada rusa, hizo acto de presencia, como número de fuerza, el Cinematógrafo pathé...»?

6 Libro citado en la nota 5, pp. 166/167.

7 Juan Antonio Cabero: Historia de la cinematografía española, (Madrid: Gráficas Cinema, 1949), pág. 34 . 
No es el momento para presentar otros casos. A partir de 1900 sabemos que entra en crisis el cine como simple documento. Los productores inician decididamente la filmación de pequeñas historias. En ocasiones se trata tan sólo de planos que se siguen, o que pueden seguirse, en discontinuidad. El espectador debe superar las lagunas. Cuando existe en la sala un presentador él es el encargado de explicar los vacíos. Comienzan a rodarse breves reconstrucciones de hechos históricos o contemporáneos. Sin embargo, hacia 1907, el cansancio del espectador no deja lugar a duda. El cine ofrece demasiado poco. Las salas cinematográficas pierden clientes.

Georges Sadoul sitúa en ese momento el nacimiento del Film d'Art y Román Gubern lo explica en pocas palabras: «el público se estaba cansando de aquel juguete óptico que ofrecía siempre los mismos asuntos, idénticos melodramas o payasadas, incapaz de una evolución madura, de un progreso dramático (...) Para salvar aquella difícil situación, los hermanos Lafitte, banqueros franceses, fundaron en 1908 la sociedad productora Film d'Art, poniendo a su cabeza a dos prohombres del teatro francés: Charles Le Bargy y André Calmette. Pensaron los Lafitte que si el cine atravesaba una crisis de argumentos, ésta podía salvarse recurriendo a los grandes temas del teatro clásico o haciendo que los escritores famosos creasen argumentos para el cine. Al mismo tiempo utilizarían a los grandes actores de la Comédie Française» ${ }^{8}$.

Ese mismo fenómeno de crisis del cinematógrafo se da en España. Lo dianostica Francos Rodríguez: «... el cinematógrafo pareció poco a cuantos asistían a estos espectáculos baratos. Los locales destinados a las películas buscaron el apoyo de compañías de verso y zarzuela...» ${ }^{9}$.

Es verdad, según dice Juan Antonio Cabero, que las salas de cine completaron generalmente sus programas con fines de fiesta llevados a cabo por cantaores, bailarines o, incluso, números circenses, como la Mujer Cañón o los leones amaestrados. Pero el propio historiador del cine español nos permite darle la razón a Francos Rodríguez. En unas carteleras de 1907 que publica, podemos leer:

«Coliseo Ena Victoria (Calle del Pez, 7). Películas. Operador: Antonio Galindo. Fin de fiesta: el transformista Torevsky, La Condesa de R..., el actor Capilla. Se representará una zarzuela titulada Cien francos».

«Ideal Polistilo (Calle Villanueva, 28). Películas y una compañía cómica». «Teatro Barbieri (Primavera, 7). Películas. Fin de fiesta: las zarzuelas Música ratonera y El barquillero» ${ }^{10}$.

De la misma manera que, en el caso de la novela de Fernández y González el gusto del público exigió la rápida y traumática terminación de la obra, la pérdida de espectadores ocasionó el cambio del espectáculo en los salones de exhibición cinematográfica. El gran número de pequeñas salas construidas para el cine reclamó una gran cantidad de atracciones que fueran completando la programa-

8 Román Gubern: Historia del cine, (Barcelona: Lumen, 1971), volumen I, pp. 84/85.

9 Francos Rodríguez, libro citado en la nota 5, pág. 166.

10 Cabero (citado), pág. 91. 
ción fílmica. El propio interés del espectador obligó a que los empresarios fueran incorporando una producción dramática peculiar. Ello explica la gran cantidad de obras en un acto que se estrena durante los años 1908 y 1909.

Además del hecho de que fueran obras en un único acto, dichas piececillas poseían otros caracteres particulares. Las condiciones de representación, el poco tiempo que permanecían en cartel, la necesidad de reducir costos, hicieron que dichas obras dramáticas no fueran sino cuadros rápidos, de escasísimo decorado y pocos personajes.

Un hecho sociológico y, por ello mismo, extratextual, se manifiesta textualmente marcando un estilo y una estética. Sería preciso, ahora, bajo esta óptica, estudiar los textos dramáticos a que me refiero. No es trabajo fácil porque pocos se han conservado. Los resultados serían, sin duda, notables.

Y debe tenerse en cuenta, también, que la rapidez de la acción de los filmes proyectados previamente y su efecto de realidad impondrían al espectador un determinado concepto del espectaculo que, de algún modo, influiría en la recepción y, luego, en la producción del texto.

Los productos humanos en general, y las creaciones artísticas en particular, no pueden apreciarse con exactitud sin situarlos en su momento y su condición sociohistórica, contextual. Y es misión de la semiótica estudiar los fenómenos lingüísticos en las relaciones de sistemas que precisamente les permiten existir. A ello he querido contribuir con este ejemplo. 